\title{
Discussion on the Ancient and Modern Chinese Cultural Confidence
}

\author{
Yan Yang \\ Academy of Marxism \\ Wuhan University of Science and Technology \\ Wuhan, China
}

\begin{abstract}
For thousands of years, China has always been developing and inheriting the traditional culture properly. In the course of history, the cultural confidence from the full confidence in the 18th century to arrogance, then to selfabandonment, and till today's lose and return, can be described as ups and downs with quite twists and turns. It is not the strong boat and heavy artillery seemingly to once defeat China, but the Western culture and Chinese excessive cultural confidence at that time. Therefore, Chinese people should make serious reflection, and rebuild Chinese cultural confidence through the analysis on the historical origin and the ups and downs of Chinese cultural confidence as well as its advantages today.
\end{abstract}

Keywords—cultural confidence; advantage; West; reconstruction

\section{INTRODUCTION}

Before the 16th century, Chinese traditional culture formed with the Chinese nation as the core, and it is regarded as the most outstanding culture in the world, better than other ethnic minorities or other world nations, so Chinese have a strong cultural confidence and cultural superiority. China's ruling kings and ordinary people in the past dynasties all praised themselves as "Kingdom of Heaven", and gradually formed a deep-rooted concept of Hua Yi, among which "Hua" represents civilization and courtesy and "Yi" means truculence and discredit. Huaxia is the central country, the center of world civilization, radiating toward all directions; "Yidi" must submit to Chinese civilization and try to take China as example; and China has the responsibility to civilize and control other minorities and all the vassal states, enlighten and domesticate them with outstanding culture and absorb their cultures into Chinese culture.

\section{THE HISTORICAL UPS AND DOWNS OF CHINESE CUltural CONFIDENCE}

From the 16th to the 18th century, the Chinese civilization reached the peak in the feudal society, and led the world in politics, philosophy, natural sciences and other fields. It enjoys a high reputation in Asia and a pivotal position in the international area. The essence of Chinese culture is the supplementation and complementation between the dominant Confucian culture and the secondary Taoism culture. In 1583, the Jesuit missionary Matteo Ricci entered Guangdong and began his missionary career. At this stage, Western missionaries have played a role in the west culture communication to China. But it can not be accepted by the Chinese people who have matured in cultural psychology and more tend to atheism; Chinese people were not interested in the exotic Christianity at first and they did not give Western culture great enthusiasm. As a country with a historical civilization of thousands of years, it still has a cultural psychology of egotism, so of course they will not value western things, which makes Christianity difficult to root and develop in China. In order to achieve the purpose of mission, the missionaries learned Chinese language, named themselves in Chinese type, wore Chinese costumes, read Confucian classics, accepted the Confucian theory; bribed the man in power, adapted with Chinese customs; and for the most important, they introduced Western advanced science and technology that the Chinese people are unfamiliar with to attract them, and then astronomy, calendar, mathematics, geography, physics, mechanical engineering, artillery manufacturing technology and other Western knowledge spread in China.

Early Western businessmen are willing to doing business with Chinese without dignity to seek great profits, which invisibly make Chinese people have more blind arrogance to their cultural confidence. From the 16th century to the 18th century, Chinese culture was conceited, and the Chinese held a general arrogant mindset.

The crisis of Chinese cultural confidence began in modern times. The Opium War as a "trade war" opened the modern history of Western powers invading China. However before the Opium War and the Sino-Japanese War, Chinese cultural subjectivity has not been lost, the concept of "Traditional Chinese values aided with modern Western ideology" also been respected. The defeat of the Sino-Japanese War in 18941895 not only declared the failure of the Westernization Movement for nearly half a century, but also laid the seeds of Chinese culture confidence loss. At the same time, from the Reform Movement of 1898 to the Revolution of 1911, the one who spread Western learning was no longer a missionary, but the advanced Chinese intellectuals. They focused on Western learning from the material level up to the spiritual level, for which they not only paid attention to the learning of advanced Western science and technology, but also focused on politicaloriented Western humanities and social sciences, and translated a large number of Western social science works. 
This marks the cultural concept transformation of modern Chinese intellectual elite, also reflects the process of Chinese cultural confidence loss. Later, in the near 50 years before 1949, the international and domestic environment was extremely poor, the country was decadent and chaotic. From the Revolution of 1911 to the warlord separatism, from Japanese aggression against China to the Chinese civil war, all the events led to the stagnation of social development and the loss of cultural confidence. China's traditional culture is gradually marginalized in the turbulent history process.

However, after the founding of New China, in the Cultural Revolution we abandoned the "human relations" and "virtue" of Chinese civilization, but also abandoned a number of baggage and chronic illness. Five thousand years of civilization is a wealth, but also is a burden. Today, the Chinese civilization uses its unprecedented clear eyes to look at the civilization in human history, which include not only the self results of yesterday, but also the non-self results. Although experienced several crisis of almost subjugation and extinction, Chinese civilization in the civilized and the ideological aspects has always been respected until the Qing Dynasty. Whether it is the five $\mathrm{Hu}$ nations' invasion for China or the Mongolian invasion for Central plain, Chinese civilization always has been a healthy and normal development in the civilized mainstream. But during the Cultural Revolution period, some excellent traditional cultures were rejected, many traditional things are abandoned, not just the burden and chronic illness.

\section{The GENERAL Situation AND Advantage ANALYsis OF TODAY'S CHINESE CULTURAL CONFIDENCE}

Throughout the history of modern China, cultural noconfidence and even cultural inferiority have become pressing issues we have to face. With the deepening of reform and opening up, China's economic strength and national power have an unprecedented development and progress, thus also lead to the wave of cultural confidence return; However, after 400 years of closed-door, when the door re-opened to the world, it is inevitable that inappropriate comparison between Chinese and Western culture and the spread of various public opinions also attack the determination of Chinese to rebuild cultural confidence. Cultural confidence is not only related to the effectiveness of national cultural development and prosperity policy, but also involves the implementation and development of "Chinese dream" that is the great rejuvenation of Chinese nation. We need to rebuild and maintain cultural confidence. Today's Chinese culture has become an indispensable part of the world's culture, Chinese traditional culture contains much value that reflects the basic cultural needs of mankind and can be generally accepted by the world, and for example the harmony concept of Chinese culture has been deeply rooted among the people. The harmony between nature and human, unity, ceaseless self-improvement, selfdiscipline and social commitment and other Chinese culture essences have been widely recognized.

Compared with Western culture, Chinese culture also has many advantages. First, we can not assess a country's cultural potential from economic accumulation, but rather from the growth rate. For example, thanks to the reform and opening up, the economic growth of the West achieved in the past few centuries has been achieved in 30 years by China through efforts, and China's sustained high-speed economic development has brought a historical upgrade of China's influence on international culture. No matter from the economic growth or the return wave of cultural confidence, we can peep the reality of Chinese cultural potential, and we believe the things that control the pace of cultural reconstruction is not the weak power, but the passion. Second, compared to the Western hegemonism, China advocates "Harmony between Nature and Human" and "Harmony Is Precious", and the "Five Principles of Peaceful Coexistence" has developed into "lasting peace, common prosperity and world harmony". Compared with Western philosophy, China's cultural concept has great cultural advantages in establishing world peace and leading win-win international relations. Thirdly, in the era of globalization, the limitations of the Western culture with competitive characteristics gradually become remarkable in the governance of global problems. For example, the value of Confucian culture is embodied in the "kindheartedness and justice" and it sets a correct view for the individual. As the teacher says, kindheartedness includes the positive meaning of loyalty and the negative meaning of forgiveness. "The man wishing to be successful himself, seeks to help others to be successful; wishing to develop himself, seeks to help others to develop" and "Do not do to others what you would not like to do to yourself " together become the pursuit and the basic standard of those who have correct views; and Confucianism on the one hand promotes "Yi Xia Zhi Fang", attaches great importance to inspire the national spirit and patriotism, and advocates the national harmony and friendly coexistence with the broad mind of "The near person is pleased to be helped, the far person will come to you" and "All men on earth are brothers". Therefore, the Confucian culture has great value for social harmony and stability. So, to rebuild Chinese cultural confidence is the call and opportunity of the times. As each Chinese who carries the great rejuvenation dream of Chinese nation shoulders the responsibility to revive the Chinese cultural confidence.

\section{How to Guide Chinese Culture TOWARD SElF- CONFIDENCE}

In order to take the path of Chinese cultural confidence, we must first realize the fundamental problem, that is, to break the Western cultural discourse hegemony. All the time the development of modern Chinese culture takes Western culture as a reference to be contrasted and transformed, and in order to truly establish our own cultural confidence, we must establish China's own standard. In addition, we should deeply study and learn the excellent theory and practice of western culture, in the meantime explore the way of cultural expansion in Western countries, and the political hegemony that is achieved through cultural expansion. Therefore, we need to establish a more rational and more objective cultural confidence, establish a Chinese theme thinking that is not controlled by Western views.

Moreover, the "cultural consciousness" needs to be promoted, the so-called cultural consciousness, borrowed from the well-known sociologist Fei Xiaotong's point of view: it refers to the people living in a certain cultural history circle 
know their own culture, and has a full understanding of its development process and the future. In other words, it is cultural self-awakening, self-reflection, and self-recreation. Cultural confidence is inseparable from cultural consciousness, and vice versa, they are mutually dependent on each other and promote each other. On the one hand, the wave of reform and opening up promotes the cultural construction while promoting economic construction, which requires us to establish dominant consciousness in the multi culture and enhance cultural awareness. On the other hand, the enhancement of cultural awareness can make better maintenance and improvement of Chinese culture in international discourse, and further the promotion of cultural soft power.

Third, to correct and rebuild cultural confidence is essential. Today, inevitably the public opinion spreads the advanced technology under the foreign cultural system, making Chinese people in the grief of indignation, and then follow the crowd, repeat what they heard, leading to the loss of identifying ability and self-thinking ability; and because of some Chinese people's cultural inferiority, they always believe foreign moon is rounder than Chinese. From the Westernization Movement "Learn from foreigners to compete with foreigners" to the "Hundred Days Restoration"-introduction of Western culture in new school, and to the "May Fourth" New Culture Movement - criticism for old culture, Western countries have always made cultural input and penetration to China, and our traditional culture is gradually being ignored. As a child, parents want us to grow up and study abroad; after school, the teachers suggest us go abroad to study professional science; after work, colleagues are competing to settle abroad. We can learn excellent cultures from foreign countries, but no matter how much imported goods we face, we can not deviate from our own culture and position and forget the beginning of determination. Our ancestors used their wisdom and their hands to create a splendid culture, and whether the Dujiangyan that makes Chengdu Plain became "land of abundance" or the Three Gorges Dam that is able to resist once-in-a-hundred-year flood, both they are the crystallization of Chinese nation wisdom, and also the important source for us to establish and strengthen our cultural confidence. The launch of Shenzhou series spaceships and that of the Dragon submersible are the results of our traditional culture in succession and innovation. Self-confidence is not arrogance, and only by a cavity of passion and self-righteous nationalist sentiment are we unable to establish cultural confidence. Patriotism is a noble sentiment, and although some people have a strong patriotic feeling, they lost the "skill package" for rational analysis. So to correct cultural confidence is it as important as a rock in the cultural revival today.

\section{CONCLUSION}

In order to absorb the world culture, we should not only struggle for the national character of culture, but also make our culture blend into the world culture, so to find our own cultural coordinates. In today's society, the economic globalization makes the international culture exchange more and more frequently. The communication platform provided for all countries is not to weaken or eliminate the national culture of the disadvantaged countries and help the strong countries to complete their cultural hegemony, but to promote the cultural essence of the various nations, to achieve multi-cultural symbiosis and promote the development and progress of world civilization. On the other hand, the world culture is the ultimate goal, what we need to do is rational development and heritage of traditional culture, constantly improve and carry forward the excellent traditional culture that is accepted by the world. China's five thousand years of cultural accumulation will shine in the world's new arena, and become the indispensable backbone force. Our culture must face the world to absorb all outstanding ideas and cultural achievements from all countries and nations. That is, the construction of national culture must be placed in the pattern of world culture, examine and surpass the national culture with advanced international cultural standard.

Without cultural confidence, we can not create the Chinese miracle, and on the way of Chinese culture rejuvenation, each of us has heavy responsibility.

\section{REFERENCES}

[1] Feng Tianyu. "Chinese Cultural History" [M]. Shanghai People's Publishing Company, 2005.

[2] Yun Shan. "Cultural Confidence: Heritage, Development and transcendence" [M]. Ideological and Theoretical Education, 2010.

[3] Wen Chaoxia, Yang Shifan. "Cultural Consciousness and Cultural Confidence" [J]. Exploration, 2013, (2).

[4] Tian Jieying, "Building a Socialist Cultural Country, Promote the Realization of Chinese Dream" [J]. Guangxi Social Sciences, 2013.

[5] Wang Yuechuan, "Establishment of Strong Cultural Strategy during Cultural Innovation" [J]. Exploration and Contention, 2012. 